\title{
Identification and Antibacterial Characterization of Endophytic Fungi from Artemisia sieberi
}

\author{
Ibtisam Mohammed Ababutain $\mathbb{D}^{1,2}$ Sahar Khamees Aldosary, ${ }^{1,2}$ \\ Amal Abdulaziz Aljuraifani, ${ }^{1,2}$ Azzah Ibrahim Alghamdi, ${ }^{1,2}$ Amira Hassan Alabdalall,,2 \\ Eida Marshid Al-Khaldi, ${ }^{1,2}$ Sumayh A. Aldakeel, ${ }^{3}$ Noor B. Almandil, ${ }^{4}$ Sayed AbdulAzeez, ${ }^{3}$ \\ and J. Francis Borgio ${ }^{3,5}$
}

\author{
${ }^{1}$ Department of Biology, College of Science, Imam Abdulrahman Bin Faisal University, P.O. Box 1982, Dammam 31441, \\ Saudi Arabia \\ ${ }^{2}$ Basic \& Applied Scientific Research Center (BASRC), Imam Abdulrahman Bin Faisal University, P.O. Box 1982, \\ Dammam 31441, Saudi Arabia \\ ${ }^{3}$ Department of Genetic Research, Institute for Research and Medical Consultations (IRMC), \\ Imam Abdulrahman Bin Faisal University, Dammam, Saudi Arabia \\ ${ }^{4}$ Department of Clinical Pharmacy Research, Institute for Research and Medical Consultations (IRMC), \\ Imam Abdulrahman Bin Faisal University, Dammam, Saudi Arabia \\ ${ }^{5}$ Department of Epidemic Diseases Research, Institute for Research and Medical Consultations (IRMC), \\ Imam Abdulrahman Bin Faisal University, Dammam, Saudi Arabia
}

Correspondence should be addressed to Ibtisam Mohammed Ababutain; iababutain@iau.edu.sa

Received 24 December 2020; Revised 2 February 2021; Accepted 22 February 2021; Published 8 March 2021

Academic Editor: Elena Sorrentino

Copyright (C) 2021 Ibtisam Mohammed Ababutain et al. This is an open access article distributed under the Creative Commons Attribution License, which permits unrestricted use, distribution, and reproduction in any medium, provided the original work is properly cited.

Endophytic fungi serve as a reservoir for important secondary metabolites. The current study focused on the antibacterial properties of endophytic fungi isolated from Artemisia sieberi. Initially, six endophytic fungi were isolated and purified from the stem of A. sieberi. Endophytic fungi were identified by morphological characteristics, as well as by molecular identification using $18 \mathrm{~S}$ rRNA gene sequencing method. All the six isolates were subjected to the preliminary screening for their antibacterial activity against nine important pathogenic bacteria using the disk-diffusion method. Crude extracts of the most active isolate were obtained using ethyl acetate. Antibacterial activity of the ethyl acetate extract was evaluated using well diffusion method on the selected isolate. The antibacterial efficiency of the selected isolate was evaluated by determining the Minimum Inhibitory Concentration (MIC). MIC values were in appreciable quantity against both Gram-positive and Gram-negative bacteria ranging from 3.125 to $6.25 \mu \mathrm{g} / \mathrm{mL}$ and 12.5 to $50 \mu \mathrm{g} / \mathrm{mL}$, respectively. This result indicated that Gram-positive bacteria were more susceptible to the endophytic fungi extract. Moreover, the molecular identification results revealed that all the isolates belong to Ascomycota and represented Aspergillus and Penicillium genera and three species: A. oryzae (three isolates), A. niger (one isolate), and $P$. chrysogenum (two isolates). All six endophytic fungi were able to inhibit the growth of at least two of the tested bacteria. Among the isolated strains, isolate AS2, which identified as P. chrysogenum, exhibited the highest antibacterial activity against all nine tested bacteria and was higher than or equal to the positive control against most of the tested bacteria. Future studies are required to isolate and identify these bioactive substances, which can be considered as a potential source for the synthesis of new antibacterial drugs to treat infectious diseases. 


\section{Introduction}

Endophytic fungi reside in the inner tissues and inside the plant cell of their hosts without causing overt symptoms and damage [1]. Studies suggest that there is a mutualistic interaction between the host and the endophytic fungi, in which the host provides shelter and nutrition, while endophytes act as chemical guards [2,3]. Research carried out so far regarding the role of endophytes in host plants indicates that they can stimulate plant growth, increase disease resistance, and improve the plant's ability to withstand environmental stress $[4,5]$. Endophytic fungi are interesting due to their potential as a source of secondary metabolites and have proven useful for novel drug discovery [6,7]. There are several studies reporting of antimicrobial activity from plant's endophytic microorganisms $[8,9]$.

Endophytic fungi are generally considered superior because of their ubiquitous and diverse nature [10]; they produce a large number of secondary metabolites greater than other endophytic microorganisms [11]. Endophytic fungi have drawn interest from natural product chemists in the search for antimicrobial or other active compounds [12]. Medicinal plants are known to harbor endophytic microorganisms, which are found to play an important role in the production of pharmaceutically important compounds [11]. Researchers found that there were large quantities of bactericidal, fungicidal, and cytotoxic metabolites produced by endophytic fungi isolated from medicinal plants [13].

Artemisia is a genus of small herbs and shrubs found in temperate regions, belonging to the family Asteraceae, comprised of about 1,000 genera and over 20,000 species. The genus Artemisia has about 500 species distributed manly in three continents: Asia, Europe, and North America [14-16]. Moreover, the genus Artemisia is raked first for its bioprospection [17].

This genus is one of the most popular plants in traditional medicines and is frequently used for the treatment of several diseases such as aging-related disorders, cancer, diabetes, hepatitis, malaria, obesity, inflammation, and infections by fungi, bacteria, and viruses [18, 19]. Several studies found that the essential oil extracted from $A$. sieberi possesses high antibacterial activities against common human pathogens $[20,21]$.

The aims of this study were to isolate and identify the endophytic fungi from Artemisia sieberi desert plant, which grows in the Eastern province of Saudi Arabia and to investigate the antibacterial activity of these fungi against some important pathogenic bacteria.

\section{Materials and Methods}

2.1. Isolation of Endophytic Fungi. Symptomless and mature Artemisia sieberi plants were selected for sampling at Eastern province of Saudi Arabia. Twelve stem samples of A. sieberi plant were collected and washed thoroughly in running tap water followed by washing with sterile distilled water. The small fragments of the stem were cut with the help of a sterilized razor blade [22] and the surfaces were sterilized with $70 \%$ ethanol for $10 \mathrm{~min}$. Then, these sterilized samples were rinsed individually three times in sterile distilled water for $1 \mathrm{~min}$, to remove the excess surface sterilants. The excess moisture was air-dried under sterile conditions. Surface sterilized explants, thus obtained, were evenly spaced in Petri dishes containing Agar medium amended with streptomycin $50 \mu \mathrm{g} / \mathrm{ml}-1$ to eliminate bacterial growth. Petri plates were sealed with Parafilm and incubated at $28^{\circ} \mathrm{C}$ until fungal growth started. The cultures were monitored every day to check for the fungal growth indicated by the hyphae emerging from the inoculated segments. The hyphal tips which grew out were subcultured onto Sabauraud's Agar (SDA) plates until pure cultures were obtained.

\subsection{Preservation and Identification of Endophytic Fungi.} Pure fungal cultures were maintained on SDA slants at $4^{\circ} \mathrm{C}$ and preserved in glycerol at $-80^{\circ} \mathrm{C}$. Identification of endophytic fungi up to the genera level was carried out using morphological microscopic characteristics (Olympus, USA, at $40 \mathrm{X})$ [23].

2.3. 18S rRNA Gene Sequencing. Molecular identification was carried out using $18 S$ rRNA gene sequencing to identify selected fungal species. Total genomic DNA was extracted from the endophytic fungi samples using the Genomic DNA Purification Kit (Promega, USA) according to the manufacturer. Briefly, cells were filtered through $0.2 \mu \mathrm{m}$ filters and grinded by freezing with liquid nitrogen. Then cells were incubated with lysis and protein precipitation solutions and eventually the extracted DNA was washed and rehydrated by a rehydration solution with incubation at $65^{\circ} \mathrm{C}$ for 1 hour. The quality of the isolated DNA was checked using agarose gel electrophoresis and NanoDrop 2000c spectrophotometer (Thermo Scientific, USA). The following primers were used for the amplification of the $18 S$ rRNA: (18S $r R N A$ forward: $5^{\prime}$-GCTTAATTTGACTCAACACGGGA- $3^{\prime}$ and $18 \mathrm{~S}$ rRNA reverse: $\quad 5^{\prime}$-AGCTATCAATCTGTCAATCCTGTC- $3^{\prime}$ ). Amplification was carried out in a thermocycler (BioRad, USA) with the following conditions: $95^{\circ} \mathrm{C}$ for $10 \mathrm{~min}$, followed by 35 cycles of $95^{\circ} \mathrm{C}$ for $1 \mathrm{~min}, 67.7^{\circ} \mathrm{C}$ for $1 \mathrm{~min}$ and $15 \mathrm{sec}$ and $72^{\circ} \mathrm{C}$ for $2 \mathrm{~min}$, and finally an extension step at $72^{\circ} \mathrm{C}$ for $5 \mathrm{~min}$. The amplified PCR products were purified using a QIAquick PCR Purification Kit (Qiagen, Germany). The purified PCR product was cycle-sequenced using BigDye Terminator Cycle Sequencing Kit (Applied Biosystems, Life Technologies Corporation, USA). The purified cycle sequence products were electrophoresed in Genetic Analyzer 3500 (Applied Biosystems, Life Technologies Corporation, USA) using POP 7 . The BLASTn was used through FungiDB to identify the name of the fungi based on the $18 \mathrm{~S}$ ribosomal RNA gene sequence.

2.4. Molecular Phylogenetic Analysis by Maximum Likelihood Method. The evolutionary history was inferred by using the Maximum Likelihood method based on the Tamura-Nei model [24]. The tree with the highest log likelihood $(-1516.91)$ is shown. Initial tree(s) for the heuristic search were obtained automatically by applying Neighbor-Join and 
BioNJ algorithms to a matrix of pairwise distances estimated using the Maximum Composite Likelihood (MCL) approach and then selecting the topology with superior log likelihood value. The tree is drawn to scale, with branch lengths measured in the number of substitutions per site. The analysis involved 84 nucleotide sequences. Codon positions included were $1 s t+2 n d+3 r d+$ Noncoding. All positions containing gaps and missing data were eliminated. There were a total of 610 positions in the final dataset. Evolutionary analyses were conducted using MEGA7 [25].

2.5. Preliminary Screening for Antibacterial Activity. Six endophytic fungi isolates (AS1, AS2, AS3, AS4, AS5, and AS6) were screened for their antibacterial activity using the disk-diffusion method [26], against the nine tested bacteria: Acinetobacter baumannii ATCCmra747, Enterobacter aerogenes ATCC13048, Escherichia coli ATCC25922, Klebsiella oxytoca ATCC700324, Klebsiella pneumonia ATCC100324, Pseudomonas aeruginosa ATCC27853, Staphylococcus aureus ATCC24213, Streptococcus agalactiae ATCC12336, and Staphylococcus epidermis ATCC12228, which were obtained from King Fahd Hospital, Al Khobar. Saudi Arabia. Endophytic fungi were cultured on SDA media at $28^{\circ} \mathrm{C}$ for 7 days. Suspensions of the tested bacteria were prepared from overnight cultures in nutrient broth. The turbidity of the suspension was adjusted to $1.5 \times 10^{8} \mathrm{CFU} / \mathrm{mL}$ using 0.5 McFarland standards and $100 \mu \mathrm{l}$ tested bacteria suspension was added to the Nutrient Agar medium (NA) plates. A sterile swab was used to evenly distribute the tested bacteria over the NA medium. The seeded plates were allowed to dry for 15 minutes. Agar plugs $(6 \mathrm{~mm}$ in diameter) of growing endophytic fungi culture were added to NA plates previously seeded with test bacteria. Disc size $6 \mathrm{~mm}$ was loaded with $100 \mu \mathrm{l}$ of Ampicillin $(0.05 \mathrm{mg} / \mathrm{mL})$, which was used as positive control, whereas nutrient broth was used as negative control. Plates were incubated at $37^{\circ} \mathrm{C}$ for $24 \mathrm{~h}$, and the inhibition zones around the agar plugs were measured to record the antibacterial activity of fungal isolates.

2.6. Fermentation and Extraction. Based on the results from preliminary screening of potent antibacterial activity, one endophytic isolate AS2 was selected for further studies. The inoculum was prepared by inoculating $1 \mathrm{~cm}^{2}$ mycelia agar plugs age 7 days into two $1000 \mathrm{~mL}$ Erlenmeyer flasks, each containing $500 \mathrm{~mL}$ of the SD broth medium. The cultures were cultivated at $28^{\circ} \mathrm{C}$ with speed of $150 \mathrm{rpm}$. After three weeks of incubation, the fermented broth and fungal biomass were separated out by centrifugation for $15 \mathrm{~min}$. Supernatant was then extracted thrice with equal volume of ethyl acetate $(1: 1, \mathrm{v} / \mathrm{v})$. The upper organic phase was concentrated to dryness under reduced pressure to obtain the crude organic extract. The crude organic extract of the isolate AS2 was kept at $4^{\circ} \mathrm{C}[27]$.

2.7. Well Diffusion Assay. Antibacterial activity of selected endophytic isolate AS2 was carried out using the modified well diffusion method [28]. Three wells were created in each plate previously incubated with the $100 \mu \mathrm{l}$ of tested bacteria at concentration of $0.5 \times 10^{8} \mathrm{CFU} / \mathrm{ml}$ using $0.5 \mathrm{McF}$ arland standards and $100 \mu \mathrm{l}$ of semisolid crude organic extract. The AS2 isolate was dissolved in $5 \mathrm{ml}$ of dimethyl sulfoxide (DMSO) to give a final concentration of $20 \mathrm{mg} / \mathrm{ml}$. Then $100 \mu \mathrm{l}$ of the late test solution was placed in one of the wells; the other two wells were served as positive and negative controls with $100 \mu \mathrm{l}$ of Ampicillin $(0.05 \mathrm{mg} / \mathrm{ml})$ and $100 \mu \mathrm{l}$ of DMSO, respectively. The plates were incubated at $37^{\circ} \mathrm{C}$ for 24 hours after which they were examined for inhibition zones. Experiments were performed in triplicate to ensure reliability.

\subsection{Determination of Minimum Inhibitory Concentration.} The determination of Minimum Inhibitory Concentration (MIC) of the selected endophytic isolate, AS2, was carried out using the 96-well microtitre plate's method [29]. Twofold dilution of Ampicillin $(0.05 \mathrm{mg} / \mathrm{ml})$ and the endophytic extract was made with Mueller-Hinton Broth (MHB). Fifty microliters of the tested bacteria at concentration of $0.5 \times 10^{8} \mathrm{CFU} / \mathrm{ml}$ was added to the previous wells. Wells numbers 11 serve as positive control containing $\mathrm{MHB}$ media and bacterial inoculum whereas wells numbers 12 serve as negative controls. Two negative controls were used $\mathrm{MHB}$ media with endophytic extract and MHB media with Ampicillin. The plates were incubated at $37^{\circ} \mathrm{C}$ for 24 hours after which they were read using a microtitre plate's reader at a wavelength of $660 \mathrm{~nm}$. Experiments were performed in triplicate to ensure reliability.

\section{Results}

3.1. Isolation and Identification of Endophytic Fungi. The stem of $A$. sieberi was colonized by endophytic fungi, from which six endophytic fungi were isolated. Based on the investigated structural morphology, all of the isolates belonged to two genera: Aspergillus and Penicillium of Ascomycota phylum. 18S rRNA gene sequencing reveled that endophytic fungi represented three species $A$. oryzae, $A$. niger, and $P$. chrysogenum, representative $18 \mathrm{~S}$ rRNA gene sequences were submitted to GenBank and the accession numbers were received (Table 1; Figures 1 and 2).

3.2. Preliminary Screening for Antibacterial Activity. The antibacterial screening results showed that all six endophytic fungi were able to inhibit the growth of at least two of the tested bacteria. Isolate number AS2 was able to inhibit the growth of all nine tested bacteria. The tested bacterium S. aureus ATCC24213 was the most sensitive bacterium toward all endophytic fungi isolates (Table 2).

3.3. Well Diffusion Assay. The results of well diffusion assay showed that the crude extract of the endophytic isolate, AS2, highly inhibited the growth of all tested bacteria. Moreover, the inhibitory activity of the isolate AS2 was higher than the positive control against some of the tested bacteria such as 
TABLE 1: Identification of endophytic fungi isolates from Artemisia sieberi.

\begin{tabular}{|c|c|c|c|}
\hline Isolates ID & Morphological identification & $\begin{array}{l}\text { Molecular identification using } 18 \mathrm{~S} \\
\text { rRNA gene sequencing }\end{array}$ & $\begin{array}{c}\text { GenBank accession } \\
\text { numbers }\end{array}$ \\
\hline $\begin{array}{l}\text { AS1/ } \\
\text { AK118SRNA }\end{array}$ & $\begin{array}{l}\text { White mycelium later became dark brownish on surface side } \\
\text { and pale brownish in the reverse }\end{array}$ & Aspergillus oryzae & MH842201 \\
\hline $\begin{array}{l}\text { AS2/ } \\
\text { AK218SRNA }\end{array}$ & $\begin{array}{l}\text { White mycelium later became bluish to dark green on surface } \\
\text { side, beige in the reverse and yellowish pigment }\end{array}$ & Penicillium chrysogenum & MH842202 \\
\hline $\begin{array}{l}\text { AS3/ } \\
\text { AK318SRNA }\end{array}$ & $\begin{array}{c}\text { Whitish mycelium later became green brownish on surface } \\
\text { side and yellowish in the reverse }\end{array}$ & Aspergillus oryzae & MN528767 \\
\hline $\begin{array}{l}\text { AS4/ } \\
\text { AK418SRNA }\end{array}$ & $\begin{array}{l}\text { Whitish mycelium later became dark brownish on surface side } \\
\text { and pale brownish in the reverse }\end{array}$ & Aspergillus oryzae & MN528766 \\
\hline $\begin{array}{l}\text { AS5/ } \\
\text { AK518SRNA }\end{array}$ & $\begin{array}{l}\text { White mycelium later became grayish to dark green on surface } \\
\text { side, beige in the reverse and yellowish pigment }\end{array}$ & Penicillium chrysogenum & MN532489 \\
\hline $\begin{array}{l}\text { AS6/ } \\
\text { AK618SRNA }\end{array}$ & $\begin{array}{l}\text { White mycelium later became black on surface side and pale } \\
\text { yellowish in the reverse }\end{array}$ & Aspergillus niger & MH842204 \\
\hline
\end{tabular}

E. aerogenes ATCC13048, K. oxytoca ATCC700324, and S. epidermis ATCC12228 (Table 3).

\subsection{Determination of Minimum Inhibitory Concentration.}

The results of MIC showed that the extract of the endophytic isolate, AS2, highly inhibited the growth of all tested bacteria. Moreover, the MIC values of the isolate AS2 extract were equal to the positive control against 5 out of 9 tested bacteria. It is worth noting that the inhibitory capacity of the extract of endophytic isolate AS2 was higher than positive control against 3 out of 9 tested bacteria (Table 4).

\section{Discussion}

Endophytes are known as valuable sources of diverse range of important natural compounds [30-32]. The metabolic compatibility for natural products secretion has been greatly influenced by natural selection [32]. The current study addressed that $A$. sieberi stem is rich in endophytic fungi in which six endophytic fungi were isolated from twelve samples. The results of the current study are consistent with a number of previous studies that isolated other endophytic fungi from different tissues of Artemisia species. For instance, 4 endophytic fungi were isolated from $A$. annua leaves [33], and 42 endophytic fungi were isolated from A. sieberi stem and root [34]. Moreover, 108 endophytic fungi were isolated from twenty samples of three Artemisia species (A. capillaris, A. indica, and A. lactiflora) [35]. These studies indicate that Artemisia species are rich in endophytic fungi.

The present study indicated that the fungal diversity was low because all the six isolates belonged to one phylum Ascomycota. There are several factors that influence the diversity of endophytes such as plant age, plant parts, seasonal collection, soil type, geographics, and other environmental conditions [36, 37]. Also, these endophytic isolates represented only two genera, Aspergillus and Penicillium, which is consistent with other studies, which found that the endophytic fungi are mainly from Ascomycota phylum $[34,38]$. The current study showed that, despite the low diversity of isolated fungi, the isolated endophytic fungus $A$. niger was not previously isolated from the genus Artemisia or its species.

The current study showed that endophytic fungi isolated from $A$. sieberi stem have the potential to inhibit the growth of at least two of the pathogenic tested bacteria which may be related to the presence of natural bioactive compounds that possessed growth inhibitory activity. This finding is consistent with other studies, which reported that endophytic fungi could be considered as a good source for secondary metabolites that have bioactive compounds [4, 38].

Recently, endophytic fungi have been isolated from some parts of medicinal plants that possessed several active biological compounds such as alkaloids, diphenyl ether, monocarboxylic acid, hydroxycinnamic acid, phenalenones, sterols, terpenoids, and xanthones [39, 40]. Mawabo et al. [41] found that A. niger isolated from Acanthus montanus stems was able to produce two chemical compounds, namely, Trypacidin A and Methylsulochrin, both of which possess the ability to inhibit tested bacteria with different degrees. Methylsulochrin had antibacterial activity against Enterococcus faecalis ATCC51299, Enterobacter cloacae BM67, and Mycobacterium smegmatis ATCC700084, whereas Trypacidin A inhibited only Mycobacterium smegmatis ATCC700084. Noor et al. [42] reported that isocoumarins derivatives which have a wide range of bioactivities are mainly produced by endophytic fungi which belong to Aspergillus and Penicillium genera. Accordingly, the antibacterial activity of the endophytic fungi isolated in the present study might be associated with the presence of one or more of these bioactive compounds in their raw extracts.

This study showed that the isolate AS2, which was identified as $P$. chrysogenum, exhibited the highest antibacterial activity against all nine tested bacteria that could be a new potential source for a broad spectrum of antibacterial agents. Second highest antibacterial activities were exhibited by AS5 and AS6 isolates, which were identified as $P$. chrysogenum and $A$. niger, respectively, and inhibited three out of the nine tested bacteria. Lastly, AS1, AS3, and AS4 isolates, which were identified as A. oryzae, inhibited only two out of the nine tested bacteria. P. chrysogenum, $A$. niger, and $A$. oryzae have been shown previously to inhibit 


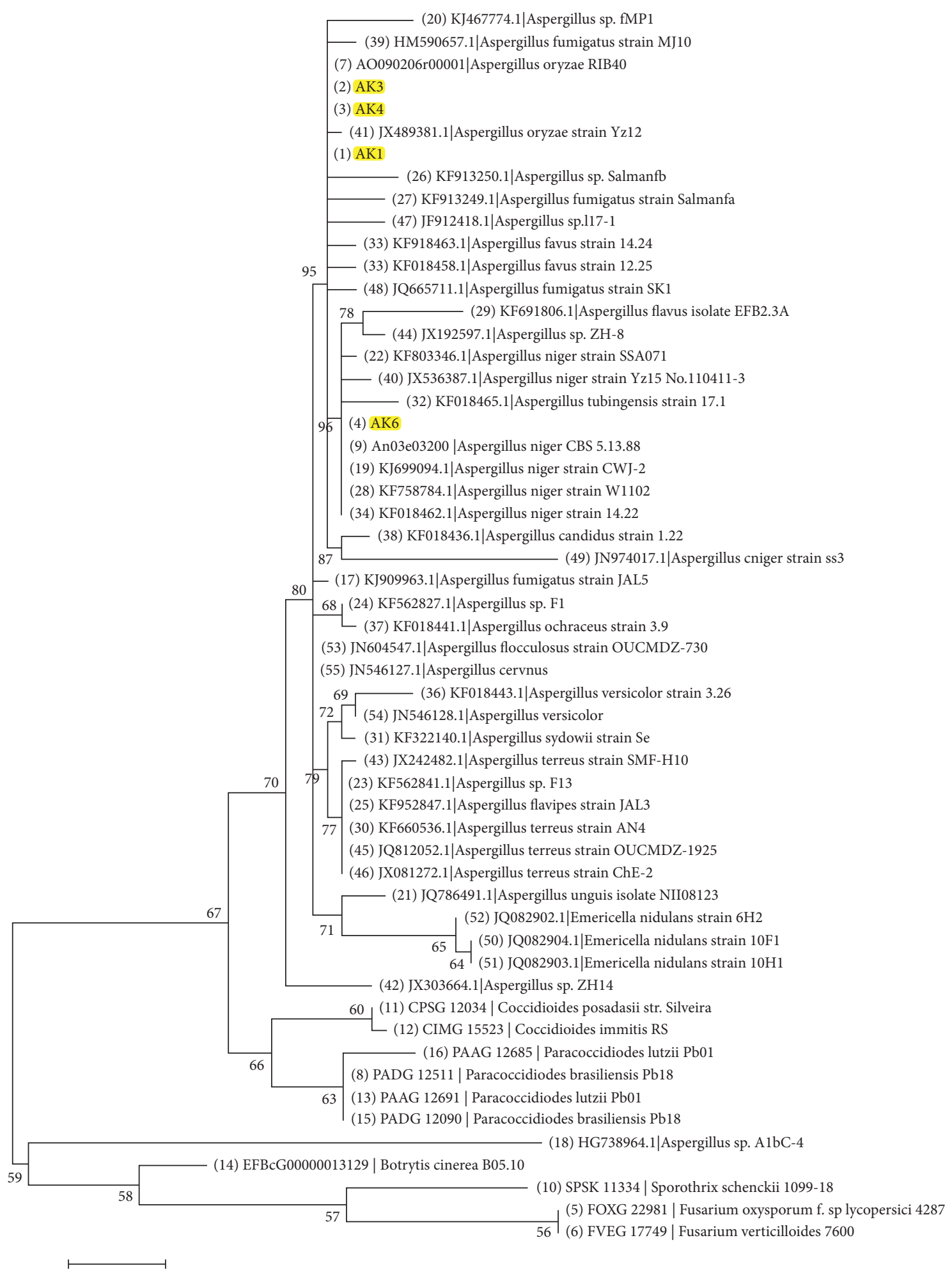

FIGURE 1: Phylogenetic trees constructed from partial $18 \mathrm{~S} r$ RNA gene sequence of strains AK1, AK3, AK4, and AK6 representing AS1, AS3, AS4, and AS6, respectively. The locations of the strains AK1, AK3, AK4 (named Aspergillus oryzae), and AK6 (named Aspergillus niger) are indicated by the yellow highlight.

the growth of pathogenic bacteria. Gashgari et al. [34] found that $P$. chrysogenum endophytic fungus isolated from some medicinal plants showed the highest inhibitory activity against pathogenic bacteria. A. niger isolated from
Hancornia species displayed excellent inhibition activity against Proteus mirabilis and S. aureus [12]. Also, Thorati and Mishra [43] found that endophytic fungus $A$. niger isolated from Rhizophora apiculata exhibited good 


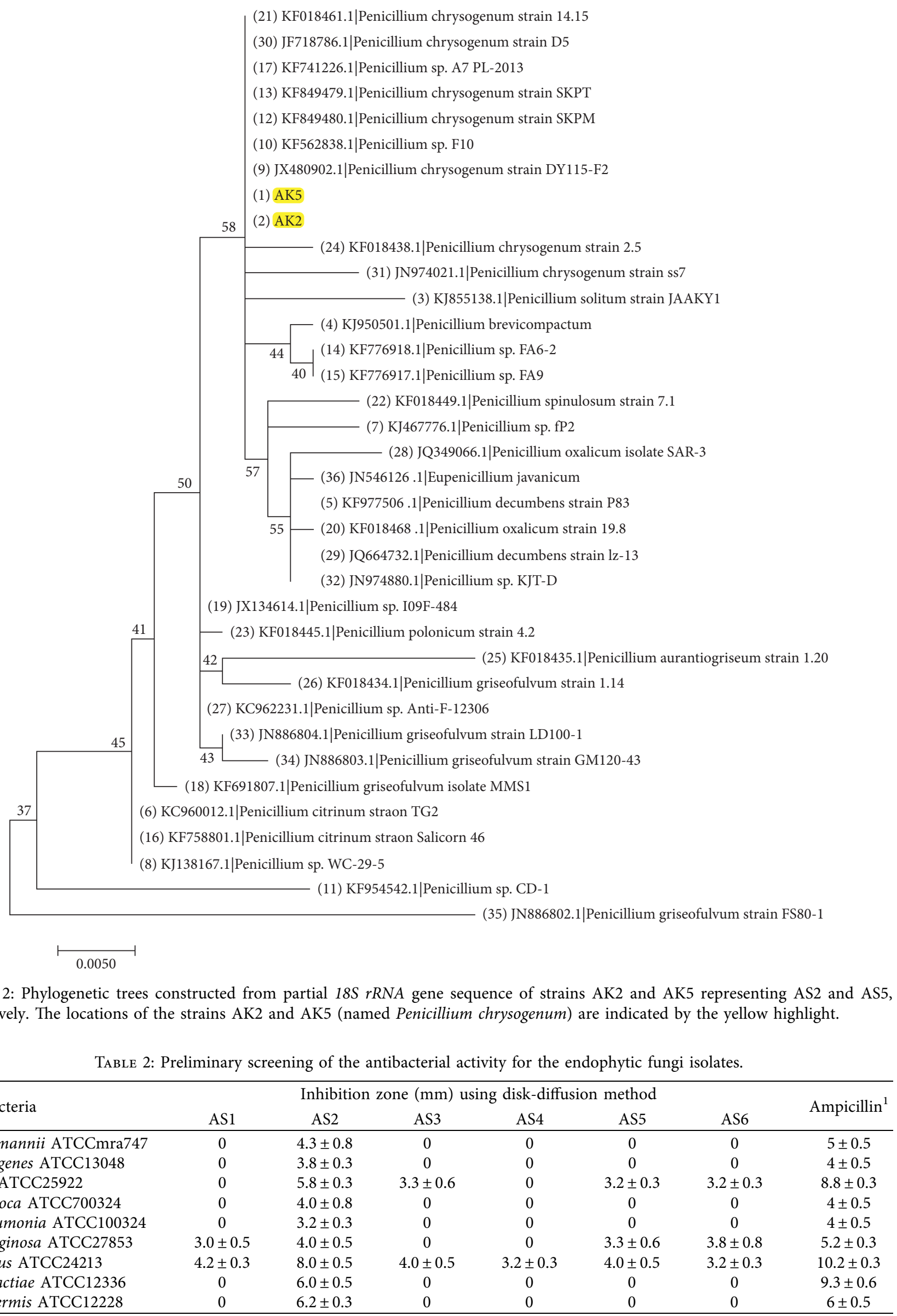

FIgURE 2: Phylogenetic trees constructed from partial $18 S$ rRNA gene sequence of strains AK2 and AK5 representing AS2 and AS5, respectively. The locations of the strains AK2 and AK5 (named Penicillium chrysogenum) are indicated by the yellow highlight.

\begin{tabular}{|c|c|c|c|c|c|c|c|}
\hline \multirow{2}{*}{ Test bacteria } & \multicolumn{6}{|c|}{ Inhibition zone $(\mathrm{mm})$ using disk-diffusion method } & \multirow{2}{*}{ Ampicillin } \\
\hline & AS1 & AS2 & AS3 & AS4 & AS5 & AS6 & \\
\hline A. baumannii ATCCmra747 & 0 & $4.3 \pm 0.8$ & 0 & 0 & 0 & 0 & $5 \pm 0.5$ \\
\hline E. aerogenes ATCC13048 & 0 & $3.8 \pm 0.3$ & 0 & 0 & 0 & 0 & $4 \pm 0.5$ \\
\hline E. coli ATCC25922 & 0 & $5.8 \pm 0.3$ & $3.3 \pm 0.6$ & 0 & $3.2 \pm 0.3$ & $3.2 \pm 0.3$ & $8.8 \pm 0.3$ \\
\hline K. oxytoca ATCC700324 & 0 & $4.0 \pm 0.8$ & 0 & 0 & 0 & 0 & $4 \pm 0.5$ \\
\hline K. pneumonia ATCC100324 & 0 & $3.2 \pm 0.3$ & 0 & 0 & 0 & 0 & $4 \pm 0.5$ \\
\hline P. aeruginosa ATCC27853 & $3.0 \pm 0.5$ & $4.0 \pm 0.5$ & 0 & 0 & $3.3 \pm 0.6$ & $3.8 \pm 0.8$ & $5.2 \pm 0.3$ \\
\hline S. aureus ATCC 24213 & $4.2 \pm 0.3$ & $8.0 \pm 0.5$ & $4.0 \pm 0.5$ & $3.2 \pm 0.3$ & $4.0 \pm 0.5$ & $3.2 \pm 0.3$ & $10.2 \pm 0.3$ \\
\hline S. agalactiae ATCC12336 & 0 & $6.0 \pm 0.5$ & 0 & 0 & 0 & 0 & $9.3 \pm 0.6$ \\
\hline S. epidermis ATCC12228 & 0 & $6.2 \pm 0.3$ & 0 & 0 & 0 & 0 & $6 \pm 0.5$ \\
\hline
\end{tabular}

${ }^{1}$ Positive control. DMSO, negative control $=0.0$ 


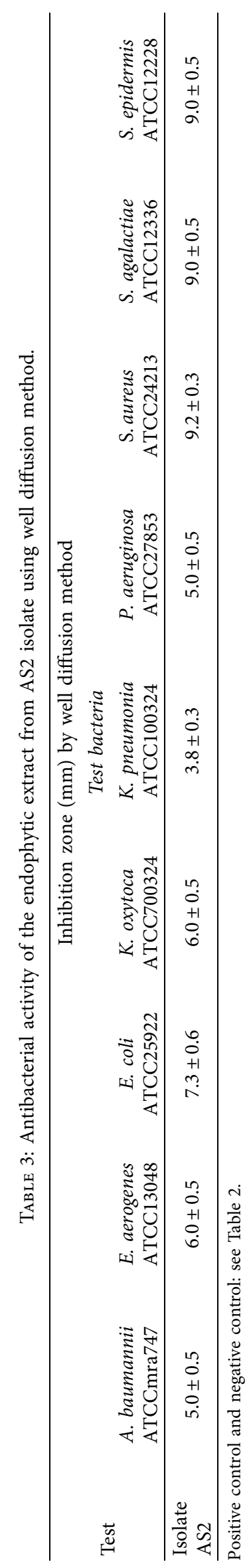




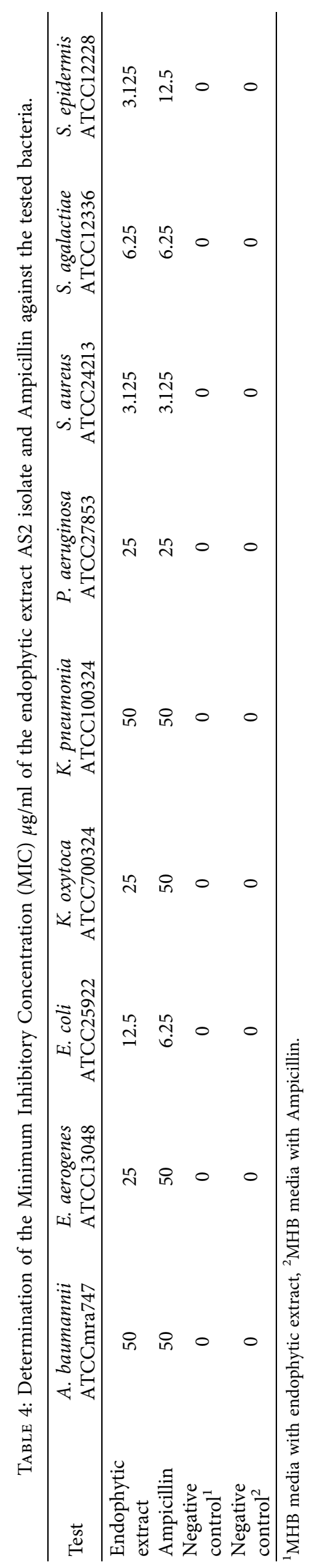


inhibition activity against pathogenic bacteria and they related that to the presence of bioactive compounds such as proteins, terpenoids, and saponins. Rani et al. [44] found that $A$. oryzae and A. niger isolated from Calotropis procera were able to inhibit the growth of both Gram-positive and Gram-negative pathogenic bacteria. Recently, Aruna et al. [45] found that the endophytic A. oryzae that was isolated from Wattakaka volubilis possessed antibacterial activity toward Micrococcus luteus and E. coli but was not able to inhibit the growth of Staphylococcus aureus and Klebsiella pneumonia. The difference in results may be due to plant type, geographical conditions, endophytic extract concentration, pathogenic bacteria strain, and endophytic fungal strain. To measure the antibacterial efficiency of the endophytic extract from the isolate AS2, the MIC was determined. The result showed appreciable MIC values against both Gram-positive and Gram-negative bacteria ranging from 3.125 to $6.25 \mu \mathrm{g} / \mathrm{mL}$ and 12.5 to $50 \mu \mathrm{g} / \mathrm{mL}$, respectively. These results indicated that Gram-positive bacteria were more susceptible than Gram-negative bacteria to the endophytic extract; this may be attributed to the nature of their cell wall structure [46].

\section{Conclusion}

The present study indicated that $A$. sieberi is rich in endophytic fungi where six endophytic fungi were isolated from twelve stem samples and all the isolates belonged to phylum Ascomycota and represented two genera Aspergillus and Penicillium. In this study, endophyte A. niger was isolated for the first time from A. sieberi. Endophytic fungi $P$. chrysogenum inhibited the growth of all tested pathogenic bacteria while the other five isolates were found to inhibit a maximum of two to three of the tested bacteria. It was interesting that these antibacterial fungi could inhibit both Gram-positive and Gram-negative pathogenic bacteria, revealing the possible existence of some broadspectrum antibacterial properties. It was noteworthy that $P$. chrysogenum isolate not only exhibited broad-spectrum activity but also was competent enough to compare with the positive control. The diameters of their inhibition zones and the MIC values against specific tested bacteria were close to or even higher than those of the positive control suggesting their potential use as new antibacterial agents. Future studies are required to isolate and identify the substance responsible for the inhibition of the pathogenic bacteria to utilize it in manufacturing drugs that could treat infections caused by antibiotic-resistant bacteria.

\section{Data Availability}

The data presented in this research are available upon request from the institutional archives of the corresponding author.

\section{Conflicts of Interest}

Authors declare that they have no conflicts of interest.

\section{Authors' Contributions}

IMA, SKA. and AAA conceived the idea; provided the samples; performed isolation, purification, identification, and antimicrobial activity experiments; and contributed to reviewing and editing the manuscript. AIA, AHA, and EMA conducted antimicrobial activity experiments and contributed to reviewing the manuscript. SAA, NBA, SA, and JFB conducted the methodology of identifying the isolates by PCR and sequencing and registered the isolates data into the GenBank sequence database, in addition to reviewing and editing the manuscript. All the authors have read and approved the final manuscript.

\section{Acknowledgments}

The authors thank the Dean of Institute for Research and Medical Consultations (IRMC) and the Director of Basic and Applied Scientific Research Centre (BASRC) at Imam Abdulrahman Bin Faisal University, Dammam, Saudi Arabia, for their continuous support and encouragement. The authors would like to thank Dr. Ahmed Alsayyah, Dr. Reem AlJindan, and Mrs. Nouf Alromaihi at King Fahd Hospital, Al Khobar, Kingdom of Saudi Arabia, for providing them with the tested microorganisms. Also, the authors thank Dr. Raheem Shahzad, Mr. Ranilo M. Tumbaga, Mr. Horace T. Pacifico, Mrs. Jee Entusiasamo Aquino, and Dr. Suriya Rehman for their assistance.

\section{References}

[1] M. Jia, L. Chen, H. L. Xin et al., "A friendly relationship between endophytic fungi and medicinal plants: a systematic review," Frontiers in Microbiology, vol. 7, p. 906, 2016.

[2] M. R. Kazenel, C. L. Debban, L. Ranelli et al., "A mutualistic endophyte alters the niche dimensions of its host plant," $A o B$ Plants, vol. 7, 2015.

[3] L. P. Singh, S. S. Gill, and N. Tuteja, "Unraveling the role of fungal symbionts in plant abiotic stress tolerance," Plant Signaling \& Behavior, vol. 6, no. 2, pp. 175-191, 2011.

[4] V. Sudha, R. Govindaraj, K. Baskar, N. A. Al-Dhabi, and V. Duraipandiyan, "Biological properties of endophytic fungi," Brazilian Archives of Biology and Technology, vol. 59, 2016.

[5] A. V. Sturz and J. Nowak, "Endophytic communities of rhizobacteria and the strategies required to create yield enhancing associations with crops," Applied Soil Ecology, vol. 15, no. 2, pp. 183-190, 2000.

[6] X.-N. Yan, R. A. Sikora, and J.-W. Zheng, "Potential use of cucumber (Cucumis sativus L.) endophytic fungi as seed treatment agents against root-knot nematode Meloidogyne incognita," Journal of Zhejiang University Science B, vol. 12, no. 3, pp. 219-225, 2011.

[7] B. Guo, Y. Wang, X. Sun, and K. Tang, "Bioactive natural products from endophytes: a review," Applied Biochemistry and Microbiology, vol. 44, no. 2, pp. 136-142, 2008.

[8] A. Aljuraifani, S. Aldosary, and I. Ababutain, "In vitro antimicrobial activity of endophytes, isolated from Moringa peregrina growing in eastern region of Saudi Arabia," $\mathrm{Na}$ tional Academy Science Letters, vol. 42, no. 1, pp. 75-80, 2019.

[9] M. M. Photolo, V. Mavumengwana, L. Sitole, and M. G. Tlou, "Antimicrobial and antioxidant properties of a bacterial 
endophyte, methylobacterium radiotolerans MAMP 4754, isolated from combretum erythrophyllum seeds," International Journal of Microbiology, vol. 2020, Article ID 9483670, 11 pages, 2020.

[10] L. Bilal, S. Asaf, M. Hamayun et al., "Plant growth promoting endophytic fungi Asprgillus fumigatus TS1 and Fusarium proliferatum BRL1 produce gibberellins and regulates plant endogenous hormones," Symbiosis, vol. 76, no. 2, pp. 117-127, 2018.

[11] H. W. Zhang, Y. C. Song, and R. X. Tan, "Biology and chemistry of endophytes," Natural Product Reports, vol. 23, no. 5, pp. 753-771, 2006.

[12] M. B. D. O. Chagas, I. Prazeres Dos Santos, L. C. Nascimento Da Silva et al., "Antimicrobial activity of cultivable endophytic fungi associated with Hancornia speciosa gomes bark," The Open Microbiology Journal, vol. 11, no. 1, p. 179, 2017.

[13] F. W. Wang, R. H. Jiao, A. B. Cheng, S. H. Tan, and Y. C. Song, "Antimicrobial potentials of endophytic fungi residing in Quercus variabilis and brefeldin A obtained from Cladosporium sp," World Journal of Microbiology and Biotechnology, vol. 23, no. 1, pp. 79-83, 2007.

[14] M. J. Abad, L. M. Bedoya, L. Apaza, and P. Bermejo, "The Artemisia L. genus: a review of bioactive essential oils," Molecules, vol. 17, no. 3, pp. 2542-2566, 2012.

[15] K. S. Bora and A. Sharma, "The GenusArtemisia: a comprehensive review," Pharmaceutical Biology, vol. 49, no. 1, pp. 101-109, 2011.

[16] J. A. T. Da Silva, "Mining the essential oils of the Anthemideae," African Journal of Biotechnology, vol. 3, no. 12, pp. 706-720, 2004.

[17] A. K. Pandey and P. Singh, "The genus Artemisia: a 2012-2017 literature review on chemical composition, antimicrobial, insecticidal and antioxidant activities of essential oils," Medicines, vol. 4, no. 3, p. 68, 2017.

[18] S. Numonov, F. Sharopov, A. Salimov et al., "Assessment of artemisinin contents in selected Artemisia species from Tajikistan (central Asia)," Medicines, vol. 6, no. 1, p. 23, 2019.

[19] A. Mannan, I. Ahmed, W. Arshad et al., "Survey of artemisinin production by diverse Artemisia species in northern Pakistan," Malaria Journal, vol. 9, no. 1, p. 310, 2010.

[20] A. Guetat, F. A. Al-Ghamdi, and A. K. Osman, "The genus Artemisia L. in the northern region of Saudi Arabia: essential oil variability and antibacterial activities," Natural Product Research, vol. 31, no. 5, pp. 598-603, 2017.

[21] M. Mahboubi and N. Farzin, "“Antimicrobial activity of Artemisia sieberi essential oilfrom central Iran," Iranian Journal of Microbiology, vol. 1, no. 2, pp. 43-48, 2009.

[22] S. Kusari, M. Lamshöft, and M. Spiteller, "Aspergillus fumigatusFresenius, an endophytic fungus fromJuniperus communisL. Horstmann as a novel source of the anticancer pro-drug deoxypodophyllotoxin," Journal of Applied Microbiology, vol. 107, no. 3, pp. 1019-1030, 2009.

[23] E. J. Vainio, K. Korhonen, and J. Hantula, "Genetic variation in Phlebiopsis gigantea as detected with random amplified microsatellite (RAMS) markers," Mycological Research, vol. 102, no. 2, pp. 187-192, 1998.

[24] K. Tamura and M. Nei, "Estimation of the number of nucleotide substitutions in the control region of mitochondrial DNA in humans and chimpanzees," Molecular Biology and Evolution, vol. 10, no. 3, pp. 512-526, 1993.

[25] S. Kumar, G. Stecher, and K. Tamura, "MEGA7: molecular evolutionary genetics analysis version 7.0 for bigger datasets," Molecular Biology and Evolution, vol. 33, no. 7, pp. 1870-1874, 2016.
[26] V. M. De Siqueira, R. Conti, J. M. De Araújo, and C. M. SouzaMotta, "Endophytic fungi from the medicinal plant Lippia sidoides Cham. and their antimicrobial activity," Symbiosis, vol. 53, no. 2, pp. 89-95, 2011.

[27] T. Sutjaritvorakul, A. J. S. Whalley, P. Sihanonth, and S. Roengsumran, "Antimicrobial activity from endophytic fungi isolated from plant leaves in Dipterocarpous forest at Viengsa district Nan province, Thailand," Journal of Agricultural Technology, vol. 7, no. 1, pp. 115-121, 2011.

[28] C. Perez, "Antibiotic assay by agar-well diffusion method," Acta Biology Medicine Experimental, vol. 15, pp. 113-115, 1990.

[29] K. Shiomi, H. Yang, J. Inokoshi et al., "Pepticinnamins, new farnesyl-protein transferase inhibitors produced by an actinomycete. II. Structural elucidation of pepticinnamin E," The Journal of Antibiotics, vol. 46, no. 2, pp. 229-234, 1993.

[30] R. Shahzad, A. L. Khan, S. Bilal, S. Asaf, and I. J. Lee, "What is there in seeds? Vertically transmitted endophytic resources for sustainable improvement in plant growth," Frontiers in Plant Science, vol. 9, p. 24, 2018.

[31] A. L. Khan, J. Hussain, A. Al-Harrasi, A. Al-Rawahi, and I.-J. Lee, "Endophytic fungi: resource for gibberellins and crop abiotic stress resistance," Critical Reviews in Biotechnology, vol. 35, no. 1, pp. 62-74, 2015.

[32] L. Padhi, Y. K. Mohanta, and S. K. Panda, "Endophytic fungi with great promises: a Review," Journal of Advanced Pharmacy Education \& Research, vol. 3, no. 3, pp. 152-170, 2013.

[33] M. A. Hussain, V. Mahajan, I. A. Rather et al., "Isolation and identification of growth promoting endophytes from Artemisia annua L. and its effects on artemisinin content," Trends in Phytochemical Research, vol. 1, no. 4, pp. 207-214, 2017.

[34] R. Gashgari, Y. Gherbawy, F. Ameen, and S. Alsharari, "Molecular characterization and analysis of antimicrobial activity of endophytic fungi from medicinal plants in Saudi Arabia," Jundishapur Journal of Microbiology, vol. 9, no. 1, Article ID e26157, 2016.

[35] W. Y. Huang, Y. Cai, S. Surveswaran, K. D. Hyde, H. Corke, and M. Sun, "Molecular phylogenetic identification of endophytic fungi isolated from three Artemisia species," Fungal Diversity, vol. 36, pp. 69-88, 2009.

[36] E. G. Fernandes, O. L. Pereira, C. C. D. Silva, C. B. P. Bento, and M. V. D. Queiroz, "Diversity of endophytic fungi in Glycine max," Microbiological Research, vol. 181, pp. 84-92, 2015.

[37] J. Martín-García, E. Espiga, V. Pando, and J. J. Diez, "Factors influencing endophytic communities in poplar plantations," Silva Fennica, vol. 45, no. 2, pp. 169-180, 2011.

[38] T. S. Suryanarayanan, "Repository of fungal endophytes at vinstrom, Chennai:waiting to be harnessed," Current Science, vol. 117, no. 9, p. 1469, 2019.

[39] P. M. Eze, J. C. Nnanna, U. Okezie et al., "Screening of metabolites from endophytic fungi of some Nigerian medicinal plants for antimicrobial activities," The EuroBiotech Journal, vol. 3, no. 1, pp. 10-18, 2019.

[40] S. S. El-hawary, A. S. Moawad, H. S. Bahr, U. R. Abdelmohsen, and R. Mohammed, "Natural product diversity from the endophytic fungi of the genus Aspergillus," RSC Advances, vol. 10, no. 37, pp. 22058-22079, 2020.

[41] I. K. Mawabo, C. Nkenfou, A. Notedji et al., "Antimicrobial activities of two secondary metabolites isolated from Aspergillus Niger, endophytic fungus harbouring stems of Acanthus montanus," Issues in Biological Sciences and Pharmaceutical Research, vol. 7, pp. 7-15, 2019. 
[42] A. O. Noor, D. M. Almasri, A. A. Bagalagel et al., "Naturally occurring Isocoumarins derivatives from endophytic fungi: sources, isolation, structural characterization, biosynthesis, and biological activities," Molecules, vol. 25, no. 2, pp. 395-489, 2020.

[43] M. Thorati and J. K. Mishra, "Antibacterial activity of crude extract from Aspergillus Niger isolated from the stilt roots of Rhizophora apiculata along South Andaman coast, India," Journal of Pharmacognosy and Phytochemical, vol. 6, no. 5, pp. 1635-1638, 2017.

[44] R. Rani, D. Sharma, M. Chaturvedi, and J. P. Yadav, "Antibacterial activity of twenty different endophytic fungi isolated from Calotropis procera and time kill assay," Clinical Microbiology, vol. 6, no. 3, p. 280, 2017.

[45] A. Aruna, M. Abhinesh, V. Bhavani, and V. K. Reddy, "Antibacterial activity of fungal endophytes isolated from Wattakaka volubilis (Linn. f.), A medicinal plant from Telangana, India," International Journal of Scientific Research in Biological Sciences, vol. 6, p. 1, 2019.

[46] H. Nikaido, "Multidrug efflux pumps of gram-negative bacteria," Journal of Bacteriology, vol. 178, no. 20, p. 5853, 1996. 